\title{
The death of expertise (in medicine)
}

The views expressed in this editorial are those of the author and do not necessarily reflect the position of the Canadian Medical Association or its subsidiaries.

E xpertise. Something we are supposed to have as physicians and surgeons. Something I always took for granted. But it seems society may not feel the same. There is some good and some bad to the concept. It no longer seems necessary to have any expertise to do very much in this world - even run a country. We are in a situation in society where people are rising to positions of power with little regard for anything except the final result and certainly without the credentials to be competent. I feel a little transparency in medicine is a good thing. Being questioned because of information patients find in Google searches may be tiring some days, but certainly ensures that the patient-physician dialogue is not "one way."

However, some Google-driven nonscientists are killing people with medical fables, such as antivaccine rhetoric. The number of websites that appear legitimate but contain weird information seems to be expanding. These websites claim to give you information that "big medicine" is afraid to supply. The reader gets the impression that we, the medical establishment, are hiding information from them - much the way Trump ran his campaign. This sours the patient-physician relationship. Sources with official titles claim medical treatments kill more people than the actual diseases and that physicians supply these treatments only in order to make money. This is the ultimate fake news that is held up as "proof" that Western medicine does not work.

So how else is medicine being affected by the loss of the importance of expertise? Every week, I, like other academics, receive dozens of invitations to sit on review panels or edi- torial boards of sundry new journals. These journals are usually open-access efforts that are published by predatory publishers and have sometimes interesting, nearly accurate titles. When the onslaught of offers first started, I was tempted to participate, and feel I have been lucky not to be tainted. But the ongoing avalanche of new titles is not unlike the misinformation being given over the Internet, as described above. The dilution of control from a few publishing houses is not in itself a bad thing, but the dilution of expertise sitting on the review boards and the resulting quality of manuscripts is somewhat worrisome. We may have reached the true Internet model of "publish everything and let the reader sort it out" - but I don't think the readers are aware that this is what is happening. Most readers of academic journals are still under the impression that articles are vetted, peer-reviewed and checked for validity. Even the old system had some difficulty guaranteeing those 3 tenets.

So, is open access an improper delivery mechanism? $\mathrm{No}$, it is not. Are new journals something to be avoided? No, they are not. There is one thing, however, that is still needed in medicine both by the reader of articles and the publishing or editing teams that deliver scientific papers. Expertise.

\section{Edward J. Harvey, MD \\ Coeditor, Canadian fournal of Surgery}

Competing interests: E.J. Harvey is the Chief Medical Officer of Greybox Healthcare (Montreal) and Chairman of the Board of NXTSens Inc. (Montreal).

DOI: $10.1503 /$ cjs.000718 